\title{
OPEN Survival outcomes after traumatic brain injury during national academic meeting days in Japan
}

\author{
Sanae Hosomi ${ }^{1,2}$, Tetsuhisa Kitamura ${ }^{2}$, Tomotaka Sobue ${ }^{2}$, Hiroshi Ogura ${ }^{1}$ \& \\ Takeshi Shimazu ${ }^{1}$
}

Surgeons and medical staff attend academic meetings several times a year. However, there is insufficient evidence on the influence of the "meeting effect" on traumatic brain injury (TBI) treatments and outcomes. Using the Japan Trauma Data Bank, we analyzed the data of TBI patients admitted to the hospital from 2004 to 2018 during the national academic meeting days of the Japanese Association for Acute Medicine, the Japanese Society of Intensive Care Medicine, the Japanese Association for the surgery of trauma, the Japan Society of Neurotraumatology and the Japan Neurosurgical Society. The data of these patients were compared with those of TBI patients admitted 1 week before and after the meetings. The primary outcome was in-hospital death. We included 7320 patients in our analyses, with 5139 and 2181 patients admitted during the nonmeeting and meeting days, respectively; their in-hospital mortality rates were $15.7 \%$ and $14.5 \%$, respectively. No significant differences in in-hospital mortality were found (adjusted odds ratio, 0.93; 95\% confidence interval, 0.78-1.11). In addition, there were no significant differences in in-hospital mortality during the meeting and non-meeting days by the type of national meeting. In Japan, it is acceptable for medical professionals involved in TBI treatments to attend national academic meetings without impacting the outcomes of TBI patients.

Traumatic brain injury (TBI) is a major cause of death and permanent disability worldwide ${ }^{1}$. Management of moderate to severe TBI alone and in combination with extracranial lesions usually starts in the emergency room (ER) with initial resuscitation before transfer to the intensive care unit (ICU). A combined medical-surgical approach is employed by multidisciplinary teams consisting of different medical professionals, such as ER physicians, intensivists, neurosurgeons, trauma surgeons, as well as ER, operation room (OP) and ICU nurses, and biomedical equipment technicians ${ }^{2}$. Dedicated trauma teams led by trained trauma surgeons have yielded improved outcomes, particularly among severely injured patients ${ }^{3,4}$. Additionally, implementing dedicated trauma care units and involving trauma-specific physician assistants seem to be beneficial ${ }^{5}$.

In this sense, the composition of hospital staff during national meeting days or off-days is thought to be associated with increased mortality risk for critically ill patients and those requiring emergent surgical interventions ${ }^{6-9}$. Annually, most medical staff attend national academic meetings. While participating in these meetings can positively impact daily medical practice, there might be a decrease in medical staff during the meeting days. Despite the growing evidence supporting the value of specialized teams and ICUs for complex patient populations, such as TBI and trauma patients, the relationship between post-TBI survival and attendance of medical staff in national academic meetings related to trauma or ICU has been insufficiently examined.

The Japanese Trauma Data Bank (JTDB) was launched in 2003 by the Japanese Association for the Surgery of Trauma (JAST; Trauma Surgery Committee) and the Japanese Association for Acute Medicine (JAAM; Committee for Clinical Care Evaluation $)^{10}$. It is similar to trauma databases in North America, Europe, and Oceania. Since 2018, 272 major emergency medical institutions across Japan have been registered in the JTDB database ${ }^{10}$. The service level of the included hospitals was similar to Level I trauma centers in the USA. Using this database, we evaluated differences in in-hospital survival after TBI during national meeting and non-meeting days in Japan. We hypothesized that there would be increased TBI-associated mortality during the national meeting days because many ER physicians and neurosurgeons attend these meetings.

${ }^{1}$ Department of Traumatology and Acute Critical Medicine, Osaka University Graduate School of Medicine, 2-15, Yamadaoka, Suita, Osaka 565-0871, Japan. ${ }^{2}$ Division of Environmental Medicine and Population Sciences, Department of Social and Environmental Medicine, Osaka University Graduate School of Medicine, 2-15, Yamadaoka, Suita, Japan. ${ }^{\boxplus}$ email: s-hosomi@hp-emerg.med.osaka-u.ac.jp 


\section{Materials and methods}

Study design, population, and setting. This retrospective cohort study used data from the JTDB database. We included TBI cases registered in the database from January 2004 to December 2018 and those transported to JTDB-participating hospitals. TBI (using the Abbreviated Injury Scale [AIS] code) was defined as a parenchymal or vascular lesion inside the skull, i.e., in the brainstem, cerebellum, and the cerebrum ${ }^{11}$. Other than isolated TBI, cases with critical injuries in other regions (AIS $\geq 3$ ) were also defined for polytrauma ${ }^{12}$. We excluded patients with a maximum head AIS score of 6 (non-survivable injury) or 9 (unspecified injury), those requiring inter-hospital transport, or those who underwent cardiopulmonary arrest upon hospital arrival ${ }^{13}$. Patients who underwent cardiopulmonary arrest were defined as those with a systolic blood pressure (SBP) of $0 \mathrm{mmHg}$ and/or heart rate of $0 \mathrm{bpm}$ on or before hospital arrival ${ }^{14}$. We also excluded cases with missing data on age, sex, Glasgow Coma Scale (GCS) score on arrival, Injury Severity Score (ISS), or survival outcome.

This study was approved by the ethics committee of Osaka University Graduate School of Medicine (No. 16260). Personal identifiers were removed from the JTDB database beforehand; thus, the need for informed consent was waived.

Japanese trauma data bank. Data were collected via the Internet from the participating institutions. Data were mainly entered by physicians and medical assistants working at JTDB-registered hospitals after they had attended an AIS-coding course ${ }^{15}$. The JTDB records trauma patients' data, including age, sex, mechanism of injury, AIS code (version 1998), ISS, vital signs upon hospital arrival, date and time of hospital arrival and discharge, medical treatments (such as interventional radiology, surgical operation, and computed tomography findings), complications, and in-hospital death ${ }^{15}$. The ISS was calculated from the top three AIS scores in nine sites classified using the AIS codes. The data used in this study are the most recent available data from this registry.

Key group definition. In this study, we focused on five national academic meetings, the JAAM ${ }^{16}$, Japanese Society of Intensive Care Medicine (JSICM) ${ }^{17}$, JAST ${ }^{18}$, Japan Society of Neurotraumatology (JSNT) ${ }^{19}$, and Japan Neurosurgical Society (JNS) ${ }^{20}$. This is because we believe that medical professionals, such as physicians, nurses, and medical engineers belonging to these academic societies, may play important roles in treating severe TBI patients after hospital admission. The JAAM, JSICM, JAST, and JNS have a total of 10,150, 9117, 2208, and 9940 members ${ }^{21}$ and $5439^{16}, 2127^{17}, 231^{18}$, and $7903^{19}$ specialists, respectively. The JNST has 814 members; however, their first examination for selecting specialists commenced in $2021^{20}$. The national meetings of JAAM, JSICM, and JNS usually last 3 consecutive days every October, March, and September, respectively, while the JAST and JSNT meetings last 2 consecutive days in May and February, respectively. Calendar days at these meetings were obtained for each year during the study period.

For analyses, we used the double-control method based on previous studies ${ }^{22}$, which allows near-perfect temporal symmetry for cases and controls and does not create time imbalance inside each pair to assess outcome differences during the exposure and control periods. In accordance with this method, we identified two groups: the exposure group, which included patients with TBI occurrence on meeting days, and the control group, which included patients with TBI occurrence during the same day of the week, 1 week before and after meetings.

Main outcome measures. The primary outcome of this investigation was in-hospital death, and the secondary outcomes were remergency department (ED) mortality, time from onset to arrival at the hospital, time from arrival to operation commencement, and duration of hospital stay.

Statistical analysis. Descriptive data are presented as counts and percentages (categorical variables) or as medians with interquartile ranges (numerical variables). Patients' characteristics and hospital care among the eligible TBI patients were compared between the exposure and control groups using Student's t-test and the $\chi^{2}$ test for categorical variables. Multivariable analysis with logistic regression models was used to compare differences in mortality outcomes between the two groups; adjusted odds ratios (ORs) and 95\% confidence intervals (CIs) were calculated. Clinically significant confounders were carefully selected from previous reports and adjusted for analyses ${ }^{6-9,23-26}$. In the multivariable logistic regression model, we adjusted for the following 12 variables: age groups (age $<18,18-64$, and $\geq 65$ years), sex (male, female), type of injury (blunt, other), mechanism of trauma (traffic accident, fall, and other), transfer system (ambulance, car/helicopter with physician, other), GCS group on arrival (severe: GCS score, 3-8; moderate: GCS score, 9-12; mild: GCS score, 13-15), hypotension (defined as SBP $\leq 90$ ) on ED admission (no, yes), operation indicated for TBI (no, yes), use of anticoagulant or antiplatelet drugs (no, yes), maximum head AIS scores ${ }^{3-5}$, multiple trauma (no, yes), and ISS. Additionally, the adjusted ORs were calculated for each meeting.

Statistical significance was defined as two-sided p-values $<0.05$ for patient characteristics or was assessed using the 95\% CI for mortality in all statistical analyses. Analyses were performed using STATA version 16 (StataCorp, College Station, TX, USA).

The study was conducted in accordance with the Declaration of Helsinki. This manuscript was written based on the STROBE statement for comprehensive reporting of cohort and cross-sectional studies ${ }^{27}$.

\section{Results}

Patient characteristics. During the study period, a total of 95,484 cases of TBI were documented (Fig. 1). After excluding victims during the non-eligible days, the data of 7320 participants (2181 in the exposure group and 5139 in the control group) were included for analyses. 


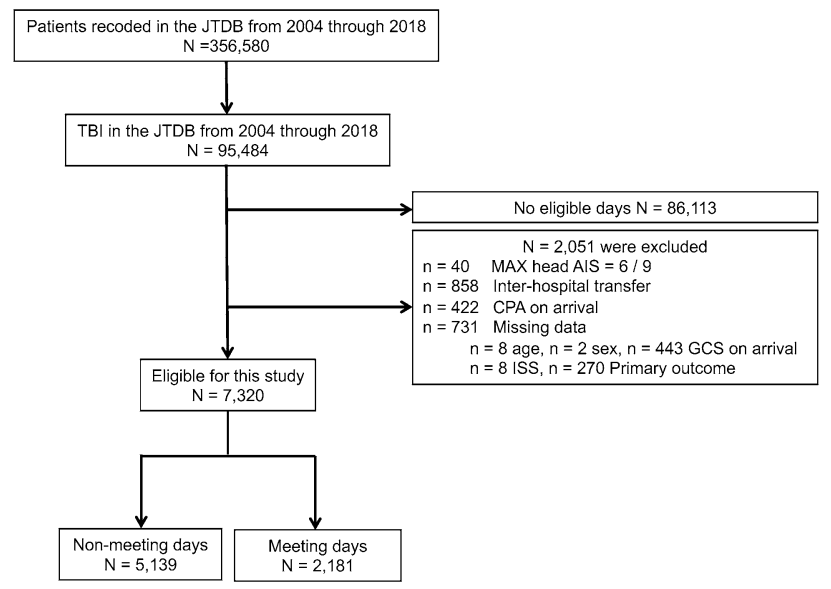

Figure 1. Flow chart of patients included in this study. JTDB Japan trauma data bank, AIS abbreviated injury scale, CPA cardiopulmonary arrest, GCS glasgow coma scale.

The characteristics of patients with TBI events during the academic meeting and non-meeting days are presented in Table 1 . Among victims in both groups, the proportion of men was approximately $67 \%$, and the mean age was 66 years. There were no differences between meeting and non-meeting days regarding the mechanism of trauma, transfer system, type of TBI, and proportion of surgeries for TBI. The proportion of hypotension on arrival, low GCS score on arrival, high AIS score, and multiple traumas, all of which indicate a severe case, were almost the same between the groups.

Mortality during meeting and non-meeting periods. Table 2 shows the proportion of in-hospital mortality and death in the ER, time from onset to arrival at the hospital, time from arrival to operation commencement, and duration of hospital stay during the meeting and non-meeting days. The proportion of participants experiencing in-hospital and ER mortality after TBI did not differ markedly between the non-meeting and meeting days (15.7\% [808/5139] versus 14.5\% [316/2181] for in-hospital mortality [adjusted OR, 0.93; 95\% CI, $0.78-1.11]$, and $1.3 \%$ [66/5139] versus $1.4 \%[31 / 2,181]$ for ER mortality [adjusted OR, 1.16; 95\% CI, 0.73-1.84]). The time from onset to arrival at the hospital, time from arrival to operation commencement, and duration of hospital stay were similar between the groups (44 [33-63] vs. 43 [32-62] $\mathrm{min}, \mathrm{p}=0.28 ; 207$ [106-4279] vs. 218 [106.5-4546.5] $\mathrm{min}, \mathrm{p}=0.69$; and $14^{5-34}$ vs. $14^{5-31}$ days, $\mathrm{p}=0.066$; respectively).

Table 3 shows the TBI outcomes during the meeting and non-meeting days as per the type of national meeting. Even after adjusting for potential confounding factors, there were no significant differences in mortality during the meeting and non-meeting days (16.0\% [230/1435] versus 12.7\% [80/632] for JAAM meetings [adjusted OR, 0.76; 95\% CI, 0.53-1.08]; 15.7\% [170/1084] versus 15.4\% [86/560] for JSICM meetings [adjusted OR, 1.06; 95\% CI, 0.75-1.48]; 17.2\% [222/1294] versus 15.7\% [112/715] for JNS meetings [adjusted OR, 0.84; 95\% CI, 0.61-1.16]); 14.5\% [110/760] versus 14.0\% [57/408] for JAST meetings [adjusted OR, 0.77; 95\% CI, 0.49-1.23]; and $13.2 \%$ [110/831] versus $12.9 \%$ [54/418] for JSNT meetings [adjusted OR, 1.23; 95\% CI, 0.80-1.88]). However, mortality associated with attendance at JAAM only tended to decrease on meeting days compared to non-meeting days [crude OR, 0.76; 95\% CI, 0.58-1.00].

\section{Discussion}

Contrary to our hypothesis, there were no significant differences in mortality among TBI patients admitted in JTDB-registered hospitals during the national academic meeting and non-meeting days. To the best of our knowledge, the present study is the first to examine the "national meeting effect" on mortality in TBI patients. These results presented unique findings and might help medical professionals attend such academic meetings and learn from them without being concerned regarding this effect.

The "weekend effect" refers to the phenomenon in which patients admitted during weekends may have more fatal outcomes than those admitted during the weekdays ${ }^{7,8}$. Poor performances in hospitals are considered a reason for this effect. In terms of instances requiring time-critical intervention for better outcomes (acute myocardial infarction, cardiac arrest, and ischemic stroke), poor outcomes during off-hours have been observed with fewer aggressive interventional procedures, less subspecialty care, more complications, increased medical errors, and varied staff composition ${ }^{28-30}$.

Regarding the "meeting effect" on trauma, it has been reported that adjusted mortality did not increase significantly for patients admitted to trauma centers with American College of Surgeons trauma verification Level 1 during the conference versus non-conference days ${ }^{6}$. Although our study focused on traumatic brain injury, our results are consistent with those from previous studies on the "meeting effect" and trauma mortality using the JTDB database ${ }^{31}$. In a report using the JTDB database, both in-hospital mortality and death in the ER were significantly lower during the day than at night among emergency trauma patients; nevertheless, weekdays/ weekends were not associated with either endpoint ${ }^{7}$. The reason why weekend effects on trauma were not obvious could be explained by the possibility that patients could immediately access the operation room or resources that 


\begin{tabular}{|c|c|c|c|c|}
\hline & Total & Non meeting days & Meeting days & \\
\hline & $\mathrm{N}=7320$ & $\mathrm{~N}=5139$ & $N=2181$ & p-value \\
\hline Age & & & & \\
\hline Median (IQR), year & $66(43-78)$ & $66(44-78)$ & $65(41-77)$ & 0.062 \\
\hline $0-17, \mathrm{n}(\%)$ & $543(7.4 \%)$ & $386(7.5 \%)$ & $157(7.2 \%)$ & 0.19 \\
\hline $18-64, \mathrm{n}(\%)$ & $2947(40.3 \%)$ & $2034(39.6 \%)$ & $913(41.9 \%)$ & \\
\hline 65-, n (\%) & $3830(52.3 \%)$ & $2719(52.9 \%)$ & $1111(50.9 \%)$ & \\
\hline Sex & & & & \\
\hline Male, n (\%) & $4930(67.3 \%)$ & $3453(67.2 \%)$ & $1477(67.7 \%)$ & 0.66 \\
\hline Type of trauma & & & & \\
\hline Blunt, n (\%) & $7144(97.6 \%)$ & $5019(97.7 \%)$ & $2125(97.4 \%)$ & 0.55 \\
\hline Mechanism of trauma & & & & \\
\hline Traffic accident, $\mathrm{n}(\%)$ & $3214(43.9 \%)$ & $2230(43.4 \%)$ & $984(45.1 \%)$ & 0.39 \\
\hline Fall, n (\%) & $3480(47.5 \%)$ & $2467(48.0 \%)$ & $1013(46.4 \%)$ & \\
\hline Others, n (\%) & $626(8.6 \%)$ & $442(8.6 \%)$ & $184(8.4 \%)$ & \\
\hline Transfer system & & & & \\
\hline Ambulance, n (\%) & $6026(82.3 \%)$ & $4245(82.6 \%)$ & $1781(81.7 \%)$ & 0.47 \\
\hline Car/helicopter with physician, n (\%) & $873(11.9 \%)$ & $609(11.9 \%)$ & $264(12.1 \%)$ & \\
\hline Others, n (\%) & $421(5.8 \%)$ & $285(5.5 \%)$ & $136(6.2 \%)$ & \\
\hline GCS at arrival & & & & \\
\hline Median (IQR) & $13(8-15)$ & $13(8-15)$ & $14(8-15)$ & 0.13 \\
\hline Mild, n (\%) & $3618(49.4 \%)$ & $2520(49.0 \%)$ & $1098(50.3 \%)$ & 0.57 \\
\hline Moderate, n (\%) & $1734(23.7 \%)$ & $1223(23.8 \%)$ & $511(23.4 \%)$ & \\
\hline Severe, n (\%) & $1968(26.9 \%)$ & $1396(27.2 \%)$ & $572(26.2 \%)$ & \\
\hline Systolic BP on arrival & & & & \\
\hline Median (IQR), mmHg & $141(120-164)$ & $142(120-164)$ & $141(120-164)$ & 0.9 \\
\hline Hypotension, n (\%) & $479(6.5 \%)$ & $344(6.7 \%)$ & $135(6.2 \%)$ & 0.43 \\
\hline Type of TBI & & & & \\
\hline Focal brain injury, n (\%) & $201(2.7 \%)$ & $147(2.9 \%)$ & $54(2.5 \%)$ & 0.36 \\
\hline Diffuse brain injury, n (\%) & $2670(36.5 \%)$ & $1875(36.5 \%)$ & $795(36.5 \%)$ & \\
\hline Other, n (\%) & $4128(56.4 \%)$ & $2880(56.0 \%)$ & $1248(57.2 \%)$ & \\
\hline Max head AIS & & & & \\
\hline Median (IQR) & $522(7.1 \%)$ & $384(7.5 \%)$ & $138(6.3 \%)$ & 0.2 \\
\hline $3, \mathrm{n}(\%)$ & $2468(33.7 \%)$ & $1727(33.6 \%)$ & $741(34.0 \%)$ & 0.083 \\
\hline $4, \mathrm{n}(\%)$ & $2998(41.0 \%)$ & $2074(40.4 \%)$ & $924(42.4 \%)$ & \\
\hline $5, \mathrm{n}(\%)$ & $1854(25.3 \%)$ & $1338(26.0 \%)$ & $516(23.7 \%)$ & \\
\hline Multiple trauma & & & & \\
\hline $\mathrm{N}(\%)$ & $2244(30.7 \%)$ & $1555(30.3 \%)$ & $689(31.6 \%)$ & 0.26 \\
\hline ISS & & & & \\
\hline Median (IQR) & $20(16-26)$ & $20(16-26)$ & $20(16-26)$ & 0.57 \\
\hline Operation for TBI & & & & \\
\hline $\mathrm{N}(\%)$ & $1284(17.5 \%)$ & $913(17.8 \%)$ & $371(17.0 \%)$ & 0.44 \\
\hline
\end{tabular}

Table 1. Information on patient background between meeting days and non-meeting days. TBI traumatic brain injury, GCS glasgow coma scale, BP blood pressure, AIS abbreviated injury scale, ISS injury severity score, $I Q R$ interquartile range.

might otherwise be occupied during normal business hours ${ }^{7}$. Similarly, the decline in the volume of scheduled surgery during the meeting periods might have contributed to the unchanged mortality.

We further assessed time differences as per the "meeting effect." In our country, not all institutions have inhouse neurosurgeons or trauma surgeons ${ }^{32}$. Hence, it is unlikely that high-risk patients were directed to such hospitals, possibly resulting in a longer duration from onset to arrival at the appropriate hospital or hospital arrival to operation commencement. However, we did not find any difference. Contrary to the aforementioned hospitals, JTDB-registered hospitals are accountable for " $24 \mathrm{~h}$ a day, 365 days a year" available resources for injured patients even during national meetings, coupled with a sophisticated prehospital system that preferentially directs patients to the correct facilities. Advance assessment of staff composition and rotation during meeting days may help against the conference effect. Compared to other countries, Japan has a smaller land area and better transportation. The on-call attending surgeons head toward the hospital, responding immediately to trauma calls and provide consistent quality of trauma care even during meetings, reflected in the unchanged time 


\begin{tabular}{|c|c|c|c|c|c|c|c|c|}
\hline & Total & $\begin{array}{l}\text { Non meeting } \\
\text { days }\end{array}$ & Meeting days & \multirow[b]{2}{*}{ p-value } & \multirow[b]{2}{*}{ Crude OR } & \multirow[b]{2}{*}{$95 \% \mathrm{CI}$} & \multirow[b]{2}{*}{ Adjusted OR } & \multirow[b]{2}{*}{$95 \% \mathrm{CI}$} \\
\hline & $N=7320$ & $\mathrm{~N}=5139$ & $N=2181$ & & & & & \\
\hline $\begin{array}{l}\text { Death at hos- } \\
\text { pital discharge, } \\
\text { n (\%) }\end{array}$ & $1124(15.4 \%)$ & $808(15.7 \%)$ & $316(14.5 \%)$ & 0.18 & 0.91 & $(0.79-1.05)$ & 0.93 & $(0.78-1.11)$ \\
\hline $\begin{array}{l}\text { Death at emer- } \\
\text { gency room, } \\
\mathrm{n}(\%)\end{array}$ & $97(1.3 \%)$ & $66(1.3 \%)$ & $31(1.4 \%)$ & 0.64 & 1.11 & $(0.72-1.70)$ & 1.16 & $(0.73-1.84)$ \\
\hline $\begin{array}{l}\text { Time from } \\
\text { onset to arrival } \\
\text { at hospital, min }\end{array}$ & $44(33-63)$ & $44(33-63)$ & $43(32-62)$ & 0.28 & & & & \\
\hline \begin{tabular}{|l|} 
Time from \\
arrival to \\
operation, min
\end{tabular} & $210(106-4361)$ & $207(106-4279)$ & $\begin{array}{l}218(106.5- \\
4546.5)\end{array}$ & 0.69 & & & & \\
\hline 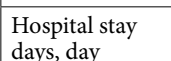 & $14(5-33)$ & $14(5-34)$ & $14(5-31)$ & 0.066 & & & & \\
\hline
\end{tabular}

Table 2. Outcomes between meeting and non-meeting days. OR odds ratio, CI confidence interval.

\begin{tabular}{|c|c|c|c|c|c|c|c|}
\hline Death at hospital discharge & Total & Non meeting days & Meeting days & Crude OR & 95\% CI & Adjusted OR & 95\% CI \\
\hline The Japanese Association for Acute Medicine, n/N (\%) & $310 / 2067(15.0 \%)$ & $230 / 1435(16.0 \%)$ & $80 / 632(12.7 \%)$ & 0.76 & $(0.58-1.00)$ & 0.76 & $(0.53-1.08)$ \\
\hline The Japanese Society of Intensive Care Medicine, n/N (\%) & $256 / 1644(15.6 \%)$ & $170 / 1084(15.7 \%)$ & $86 / 560(15.4 \%)$ & 0.98 & $(0.74-1.29)$ & 1.06 & $(0.75-1.48)$ \\
\hline The Japan Neurosurgical Society, n/N (\%) & $334 / 2009(16.6 \%)$ & $222 / 1294(17.2 \%)$ & $112 / 715(15.7 \%)$ & 0.9 & $(0.70-1.15)$ & 0.84 & $(0.61-1.16)$ \\
\hline $\begin{array}{l}\text { The Japanese Association for the Surgery of Trauma, } \\
\mathrm{n} / \mathrm{N}(\%)\end{array}$ & $167 / 1168(14.3 \%)$ & $110 / 760(14.5 \%)$ & $57 / 408(14.0 \%)$ & 0.96 & $(0.68-1.36)$ & 0.77 & $(0.49-1.23)$ \\
\hline The Japan Society of Neurotraumatology, n/N (\%) & $164 / 1249(13.1 \%)$ & $110 / 831(13.2 \%)$ & $54 / 418(12.9 \%)$ & 0.97 & $(0.69-1.38)$ & 1.23 & $(0.80-1.88)$ \\
\hline
\end{tabular}

Table 3. Primary Outcomes between meeting days and non-meeting days as per the type of national meeting. OR odds ratio, CI confidence interval.

from the arrival to operation. Furthermore, no difference in time outcome also contributed to the unchanged mortality during meeting days.

In our study, which focused on TBIs, only mortality associated with JAAM attendance tended to decrease on meeting than on non-meeting days; however, unlike previous studies, no significant differences were observed ${ }^{31}$. Although the definitive reasons for this remain unclear, this finding could be attributed to the fact that more ER physicians belong to the JAAM compared to the other four societies. Strong leadership, teamwork, and technical skills are essential for team performance and patient care in initial trauma management ${ }^{33,34}$, and more experienced ER physicians or trauma surgeons would encourage their hospitals to lead the treatment of hospitalized patients during academic national meeting dates 9

Considering TBI treatment, factors associated with consistent, high-quality care include appropriate staffing, prompt triage and decision making, and establishing inter-facility consultations. Trauma centers are required to be fully staffed and resourced irrespective of meeting $\mathrm{s}^{34,35}$. Based on our results, medical professionals involved in TBI treatments in Japan can attend national academic meetings because through these meetings they might learn regarding the latest findings on TBI cases. Importantly, owing to the new coronavirus disease (COVID-19) pandemic, organizers of these conferences may consider offering optional opportunities for Web conferences so that trauma centers or ICUs would maintain their care capacities while medical professionals would benefit from educational opportunities that academic meetings provide. Therefore, it is important to continue monitoring the "meeting effect" concerning the survival of TBI patients.

Our study had several limitations. First, we did not address the influence of the location of the hospital providing the data. For instance, it has been shown that TBI mortality rates are higher in rural areas of the United States ${ }^{35}$. Therefore, our results might be different if we considered information regarding the regionality of hospitals. Second, we did not obtain detailed information on medical staff attending national meetings and non-participants at the hospitals. Additionally, we focused on TBI occurrence during five representative national meetings to simplify our research. The logical next step in this field of research would be the examination of both regional and international meeting periods. Third, the study primarily included major critical care cases; therefore, the results cannot be extended to other institutions. Fourth, this was an observational study, and other unknown confounding factors possibly existed. Finally, the validity and integrity of the data, and ascertainment bias, were potential limitations of our study. However, uniform data collection based on the JTDB registering system and large sample sizes should minimize these potential sources of bias. 


\section{Conclusions}

In this population, there were no significant differences in outcomes, such as in-hospital death, ED mortality, duration from onset to arrival at the hospital, duration of hospital arrival to operation commencement, and duration of hospital stay after TBI, between the meeting and non-meeting days.

Received: 30 March 2021; Accepted: 15 July 2021

Published online: 26 July 2021

\section{References}

1. Roozenbeek, B., Maas, A. I. \& Menon, D. K. Changing patterns in the epidemiology of traumatic brain injury. Nat. Rev. Neurol. 9(4), 231-236. https://doi.org/10.1038/nrneurol.2013.22 (2013).

2. Stocchetti, N. et al. Severe traumatic brain injury: Targeted management in the intensive care unit. Lancet Neurol. 16(6), 452-464. https://doi.org/10.1016/S1474-4422(17)30118-7 (2017).

3. Davis, K. A. et al. Trauma team oversight improves efficiency of care and augments clinical and economic outcomes. J. Trauma 65(6), 1236-1242. https://doi.org/10.1097/TA.0b013e31818ba311 (2008).

4. Mains, C. et al. Staff commitment to trauma care improves mortality and length of stay at a Level I Trauma Center. J. Trauma 66(5), 1315-1320. https://doi.org/10.1097/TA.0b013e31819d96d8 (2009).

5. Sise, C. B. et al. Resource commitment to improve outcomes and increase value at a Level I Trauma Center. J. Trauma 70(3), 560-568. https://doi.org/10.1097/TA.0b013e31820c7b79 (2011).

6. Jenkins, P. C., Painter, S., Bell, T. M., Kline, J. A. \& Zarzaur, B. L. The conference effect: National surgery meetings are associated with increased mortality at trauma centers without American College of Surgeons verification. PLoS ONE 14(3), e0214020. https:// doi.org/10.1371/journal.pone.0214020 (2019).

7. Hirose, T. et al. Impact of nighttime and weekends on outcomes of emergency trauma patients: A nationwide observational study in Japan. Medicine (Baltim.) 99(1), e18687. https://doi.org/10.1097/MD.0000000000018687 (2020).

8. Schneider, E. B. et al. Beating the weekend trend: Increased mortality in older adult traumatic brain injury (TBI) patients admitted on weekends. Haider J. Surg. Res. 177(2), 295-300. https://doi.org/10.1016/j.jss.2012.06.022 (2012).

9. Jena, A. B., Prasad, V., Goldman, D. P. \& Romley, J. Mortality and treatment patterns among patients hospitalized with acute cardiovascular conditions during dates of national cardiology meetings. JAMA Intern. Med. 175(2), 237-244. https://doi.org/10. 1001/jamainternmed.2014.6781 (2015).

10. Japan Trauma Care and Research. Japan Trauma Databank Annual Report 2014-2018, 2019 (Japan Trauma Care and Research, 2019).

11. Association for the Advancement of Automatic Medicine. The Abbreviated Injury Scale, 1990 Revision, Update 98 (Association for the Advancement of Automatic Medicine, 2001).

12. Butcher, N. \& Balogh, Z. J. AIS $>2$ in at least two body regions: A potential new anatomical definition of polytrauma. Injury 43(2), 196-199. https://doi.org/10.1016/j.injury.2011.06.029 (2012).

13. Härtl, R. et al. Direct transport within an organized state trauma system reduces mortality in patients with severe traumatic brain injury. J. Trauma 60(6), 1250-1256. https://doi.org/10.1097/01.ta.0000203717.57821.8d (2006).

14. Katayama, Y. et al. Pelvic angiography is effective for emergency pediatric patients with pelvic fractures: A propensity-scorematching study with a nationwide trauma registry in Japan. Eur. J. Trauma Emerg. Surg. https://doi.org/10.1007/s00068-01901154-w (2019).

15. Japan Trauma Care and Research. Japan Trauma Data Bank Annual Report 2014-2018 (Japan Trauma Care and Research, 2019).

16. Japanese Association for Acute Medicine. Homepage. https://www.jaam.jp. Accessed 14 June 2021.

17. Japanese Society of Intensive Care Medicine. Homepage. http://www.jsicm.org/. Accessed 14 June 2021.

18. The Japanese Association for the Surgery of Trauma. Homepage. http://www.jast-hp.org/en/. Accessed 14 June 2021.

19. The Japan Neurosurgical Society. Homepage. http://jns.umin.ac.jp/english/about. Accessed 14 June 2021.

20. The Japan Society of Neurotraumatology. Homepage. http://www.neurotraumatology.jp. Accessed 14 June 2021.

21. Directory of Association. http://gakkai.jst.go.jp. Accessed 14 June 2021.

22. Sado, J. et al. Full moon and out-of-hospital cardiac arrest in Japan-Population-based, double-controlled case series analysis. Circ. Rep. 1(5), 212-218. https://doi.org/10.1253/circrep.CR-18-0030 (2019).

23. Stocchetti, N. et al. Clinical review: Neuromonitoring-An update. Crit. Care 17(1), 201. https://doi.org/10.1186/cc11513 (2013).

24. Corps, K. N., Roth, T. L. \& McGavern, D. B. Inflammation and neuroprotection in traumatic brain injury. JAMA Neurol. 72(3), 355-362. https://doi.org/10.1001/jamaneurol.2014.3558 (2015).

25. Carteron, L., Taccone, F. S. \& Oddo, M. How to manage blood pressure after brain injury? Minerva Anestesiol. 83(4), 412-421. https://doi.org/10.23736/S0375-9393.16.11696-7 (2017).

26. Beynon, C., Hertle, D. N., Unterberg, A. W. \& Sakowitz, O. W. Clinical review: Traumatic brain injury in patients receiving antiplatelet medication. Crit. Care 16(4), 228. https://doi.org/10.1186/cc11292 (2012).

27. Gallo, V. et al. Strengthening the Reporting of OBservational studies in Epidemiology-Molecular Epidemiology STROBE-ME: An extension of the STROBE statement. J. Clin. Epidemiol. 64(12), 1350-1363. https://doi.org/10.1016/j.jclinepi.2011.07.010 (2011).

28. Kostis, W. J. et al. Weekend versus weekday admission and mortality from myocardial infarction. N. Engl. J. Med. 356(11), 10991109. https://doi.org/10.1056/NEJMoa063355 (2007).

29. Peberdy, M. A. et al. National Registry of Cardiopulmonary Resuscitation. Survival from in-hospital cardiac arrest during nights and weekends. JAMA 299(7), 785-792. https://doi.org/10.1001/jama.299.7.785 (2008).

30. Saposnik, G., Baibergenova, A., Bayer, N. \& Hachinski, V. Weekends: A dangerous time for having a stroke? Stroke 38(4), 12111215. https://doi.org/10.1161/01.STR.0000259622.78616.ea (2007).

31. Yumoto, T., Naito, H., Ihoriya, H., Yorifuji, T. \& Nakao, A. Mortality in trauma patients admitted during, before, and after national academic emergency medicine and trauma surgery meeting dates in Japan. PLoS ONE 14(1), e0207049. https://doi.org/10.1371/ journal.pone.0207049 (2019).

32. Ono, Y. et al. The off-hour effect on trauma patients requiring subspecialty intervention at a community hospital in Japan: A retrospective cohort study. Scand. J. Trauma Resusc. Emerg. Med. 23, 20. https://doi.org/10.1186/s13049-015-0095-1 (2015).

33. Carr, B. G. et al. Does the trauma system protect against the weekend effect? J. Trauma 69(5), 1042-1047. https://doi.org/10.1097/ TA.0b013e3181f6f958 (2010)

34. MacKenzie, E. J. et al. A national evaluation of the effect of trauma-center care on mortality. N. Engl. J. Med. 354(4), 366-378. https://doi.org/10.1056/NEJMsa052049 (2006).

35. Brown, J. B., Kheng, M., Carney, N. A., Rubiano, A. M. \& Puyana, J. C. Geographical disparity and traumatic brain injury in America: Rural areas suffer poorer outcomes. J. Neurosci. Rural Pract. 10(1), 10-15. https://doi.org/10.4103/jnrp.jnrp_310_18 (2019). 


\section{Acknowledgements}

This study was funded by a Grant-in-Aid for Scientific Research (C) from the Japan Society for the Promotion of Science (Grant Number: 18K08886), and a Grant from Zenkyoren (National Mutual Insurance Federation of Agricultural Cooperatives) awarded to S.H. The funders had no role in the study design, collection, analysis, interpretation of data, and manuscript writing. The authors thank the emergency medical service personnel, nurses, neurosurgeons, and emergency medicine physicians who participated in the JTDB. We also thank our colleagues from the Osaka University Center of Medical Data Science, Advanced Clinical Epidemiology Investigator's Research Project for providing insight and expertise in the research.

\section{Author contributions}

S.H., T.Sobue and T.K. designed the study and wrote the manuscript. S.H. and T.K. performed statistical analysis. H.O. and T.Shimazu critically revised the manuscript for important intellectual content. All authors read and approved the final manuscript.

\section{Competing interests}

The authors declare no competing interests.

\section{Additional information}

Correspondence and requests for materials should be addressed to S.H.

Reprints and permissions information is available at www.nature.com/reprints.

Publisher's note Springer Nature remains neutral with regard to jurisdictional claims in published maps and institutional affiliations.

(c) (i) Open Access This article is licensed under a Creative Commons Attribution 4.0 International License, which permits use, sharing, adaptation, distribution and reproduction in any medium or format, as long as you give appropriate credit to the original author(s) and the source, provide a link to the Creative Commons licence, and indicate if changes were made. The images or other third party material in this article are included in the article's Creative Commons licence, unless indicated otherwise in a credit line to the material. If material is not included in the article's Creative Commons licence and your intended use is not permitted by statutory regulation or exceeds the permitted use, you will need to obtain permission directly from the copyright holder. To view a copy of this licence, visit http://creativecommons.org/licenses/by/4.0/.

(c) The Author(s) 2021 